\title{
Application of Discovery Learning Based Video Media In Improving Learning Results Themes 5 Class V SDN Petompon 02 Semester 1
}

\author{
Ade Febriyanto Wigar \\ SDN Petompon 02 Semarang \\ wigarade@gmail.com
}

\section{Article History \\ accepted 14/11/2020}

approved 21/11/2020 published 26/11/2020

\begin{abstract}
In developing students' potential, the learning process must provide learning experiences for students. In its development the way students learn there are changes according to the times. In the era of the 21st century, all activities in learning involve technology. There needs to be an implementation that is able to provide a learning experience for students as well as provide space for technology in the learning process. This Classroom Action Research consists of two cycles. As subjects in this study were students of class VB SDN Petompon 02 with a total of 37 students. In collecting data on learning outcomes using test and non-test techniques. The instruments used include evaluation questions, assessment rubrics and assessment instruments. The results of the achievement in the first cycle of students completed reaching 24 students with a percentage of 65\% and an increase in the second cycle where there were 28 students who completed with a presentation of $78 \%$. The results showed that the use of the Discovery Learning model based on video learning was able to improve learning outcomes in Theme 5 Ecosystems in class VB SDN Petompon 02 Semarang.

Keywords: Discovery Learning, Learning Videos, Learning outcome
\end{abstract}

\begin{abstract}
Abstrak
Dalam mengembangkan potensi siswa proses pembelajaran harus memberikan pengalaman belajar bagi siswa. Dalam perkembangannya cara belajar siswa terdapat perubahan sesuai perkembangan zaman. Di era abad 21 semua aktifitas dalam pembelajaran melibatkan teknologi. Perlu adanya sebuah implementasi yang mampu memberikan pengalaman belajar bagi siswa sekaligus memberi ruang teknologi dalam proses pembelajaran. Penelitian Tindakan Kelas ini terdiri dari dua siklus. Sebagai subjek dalam penelitian ini adalah siswa kelas VB SDN Petompon 02 dengan jumlah siswa 37 orang. Dalam pengumpulan data hasil belajar menggunakan teknik test dan non tes. Instrumen yang digunakan meliputi soal evaluasi, rubrik penilaian dan instrument penilaian. Hasil ketercapaian pada siklus I siswa tuntas mencapai 24 siswa dengan presentase $65 \%$ dan mengalami peningkatan pada siklus II dimana terdapat 28 siswa tuntas dengan presentasi sebesar $78 \%$. Hasil penelitian bahwa penggunaan model Discovery Learning berbasis video pembelajaran mampu meningkatkan hasil belajar Tema 5 Ekosistem pada siswa kelas VB SDN Petompon 02 Semarang

Kata kunci: Discovery Learning, Video pembelajaran, Hasil Belajar
\end{abstract}

Social, Humanities, and Education Studies (SHEs): Conference Series p-ISSN 2620-9284 https://jurnal.uns.ac.id/shes 


\section{PENDAHULUAN}

Dalam perkembangannya Pendidikan menjadi kebutuhan yang mendasar bagi setiap manusia. Implementasi dalam kegiatan belajar mengajar pada satuan pendidikan Sekolah Dasar belum mampu mengakomodasi tujuan pendidikan. Hal tersebut dikarenakan pembelajaran yang terjadi kurang bermakna bagi peserta didik. Perkembangan ilmu pengetahuan dan teknologi di Abad 21 yang semakin pesat membuat karakteristik peserta didik mengalami perubahan. Dimana peserta didik masuk dalam kategori generasi milenial atau generasi Z. Sehingga diperlukan perubahan orientasi dalam kegiatan belajar. Sebagai pendidik harus mampu mengikuti perkembangan dan tuntutan zaman. Perlu adanya implementasi penerapan teknologi dalam proses pembelajaran. Sehingga dalam penerapannya sesuai dengan karakteristik peserta didik.

Menurut Suharsimi A. (2004) dalam Sukajati (2008) ada tiga kata yang membentuk pengertian PTK, yaitu penelitian, tindakan, dan kelas. Penelitian adalah kegiatan mencermati suatu obyek dengan menggunakan aturan metodologi tertentu untuk memperoleh data atau informasi yang bermanfaat dalam meningkatkan mutu suatu hal, serta menarik minat dan penting bagi peneliti. Menurut Hosnan (2014:282).

Pengertian Discoveri Learning menurut beberapa ahli: Menurut Bruner (Lefancois dalam Emetembun, 1986:103) "Model Discovery Learning didefinisikan sebagai proses pembelajaran yang terjadi bila pelajar tidak disajikan dalm bentuk finalnya, tetapi diharapkan mengorganisasi sendiri. Menurut Budiningsih (2005:43), "Model Discovery Learning adalah cara belajar memahami konsep, arti, dan hubungan melalui proses intuitif untuk akhirnya sampai kepada suatu kesimpulan".

Dalam kajian pustaka.com, discovery learning adalah suatu model untuk mengembangkan cara belajar aktif dengan menemukan sendiri, menyelidiki sendiri, maka hasil yang diperoleh akan setia dan tahan lama dalam ingatan. Melalui belajar penemuan, siswa juga bisa belajar berpikir analisis dan mencoba memecahkan sendiri masalah yang dihadapi. Video merupakan serangkaian gambar gerak yang disertai suara yang membentuk suatu kesatuan yang dirangkai menjadi alur, dengan pesanpesan di dalamnya untuk ketercapaian tujuan pembelajaran yang disimpan dengan proses penyimpanan pada media pita atau disk (Arsyad, 2004:36 dalam Rusman dkk 2011:218) dalam meaningaccordingtoexperts. blogspot.com).

Dari pengertian yang telah dijabarkan tersebut dapat disimpulkan bahwa Discovery Learning merupakan model pembelajaran yang membimbing peserta didik untuk menemukan dan mengelola segala informasi dengan arahan dan bimbingan pendidik. Model discovery learning memiliki ciri tersendiri sehingga dapat ditemukan perbedaan dengan model pembelajaran lainnya, berikut tiga ciri utama belajar dengan model pembelajaran discovery learning atau penemuan yaitu: 1) Mengeksplorasi dan memecahkan masalah untuk menciptakan, menggabungkan dan menggeneralisasi pengetahuan 2) Berpusat pada peserta didik 3) Kegiatan untuk menggabungkan pengetahuan baru dan pengetahuan yang sudah ada.

Menurut Syah (2004:244) dalam mengaplikasikan metode Discovery Learning di kelas, ada beberapa prosedur yang harus dilaksanakan dalam kegiatan belajar mengajar secara umum sebagai berikut: stimulation (Stimulasi/Pemberian Rangsangan); Problem Statement (Pernyataan/ Identifikasi Masalah); Collection (Pengumpulan Data); Processing (Pengolahan Data); Verification (Pembuktian); Generalization (Menarik Kesimpulan/Generalisasi). 
Penelitian yang relevan pernah dilakukan oleh Naila Ayadia pada tahun 2014 dengan Judul Penerapan Model Pembelajaran Discovery Learning dengan Scientific Approach untuk Meningkatkan Keterampilan Proses Sains Siswa SMA. Dalam penelitian tersebut diperoleh data bahwa Penerapan model pembelajaran discovery learning dengan scientific approach dapat meningkatkan keterampilan proses sains siswa dengan peningkatan signifikan sebesar $13,28 \%$ Sesuai latar belakang masalah dan rumusan masalah yang telah dipaparkan, maka tujuan penelitian adalah untuk meningkatkan hasil belajar siswa kelas $\mathrm{V}$ semester 1 tema 5 Ekosistem dengan menggunakan media belajar audio visual berbasis Discovery Learning di SDN Petompon 02 Tahun pelajaran 2020/2021.

\section{METODE}

Dalam Penelitian tindakan kelas peneliti menggunakan metode kuantitatif yang diperoleh dari hasil belajar peserta didik. Waktu penelitian tindakan kelas ini dilakukan pada semester 1 tahun ajaran 2020/2021. Penelitian dilaksanakan dengan dua siklus. Subjek penelitian adalah peserta didik kelas VB SDN Petompon 02 Semarang yang terdiri dari 37 siswa. Teknik dan alat pengumpulan data meliputi dokumentasi, observasi, dan tes. Teknik dokumentasi dilakukan untuk mengumpulkan dokumen atau data-data yang mendukung penelitian seperti jumlah siswa, daftar nama siswa, dan nilai ulangan siswa Tema $\mathrm{V}$ sebelum penelitian. Observasi dilaksanakan untuk pengumpulan data terkait keaktifan peserta didik dalam proses pembelajaran dan ketercapaian rencana pelaksanaan pembelajaran dengan menggunakan lember observasi. Tes dilakukan untuk mengukur aspek kognitif keberhasilan peserta didik dalam belajar. Data kuantitatif berupa hasil belajar kognitif yang dianalisis dengan menggunakan teknik analisis deskriptif. Analisis tingkat keberhasilan atau prosentase ketuntasan belajar siswa diambil setelah proses belajar mengajar berlangsung pada setiap siklusnya, dilakukan dengan cara memberikan evaluasi atau tes akhir siklus berupa soal tes tertulis. Penyajian data kuantitatif disajikan dalam bentuk persentase dan angka.

\section{HASIL DAN PEMBAHASAN}

\section{Pra Siklus}

Pada kegiatan ini dilakukan untuk mengetahui kemampuan awal peserta didik dalam pemahaman materi belajar. Pada kegiatan pra siklus ini juga digunakan sebagai data awal yang berfungsi untuk pembending pada siklus berikutnya. Dari hasil pengumpulan dan pengolahan data diperoleh hasil sebagai berikut:

Tabel 1. Rekapitulasi Hasil Belajar Pra Siklus 


\begin{tabular}{|c|c|c|c|c|c|c|c|}
\hline NO & $\begin{array}{c}\text { NAMA SISWA } \\
\end{array}$ & NILAI & KETERANGAN & NO & NAMA SISWA & NILAI & KETERANGAN \\
\hline 1 & MUHAMMAD KATRI DARUSSALAM & 90 & TUNTAS & 20 & JALESA PRAMESH KHATAMI & 80 & TUNTAS \\
\hline 2 & KESYA PUPUT ARYANTI & 40 & TIDAK TUNTAS & 21 & JOVA BRATA SANJOYO & 80 & TUNTAS \\
\hline 3 & ALIA SHOFIA RAHMADHANI & 50 & TIDAK TUNTAS & 22 & KANAHAYA ZETA AZARIN & 50 & TIDAK TUNTAS \\
\hline 4 & ALMIRA ALIFIA CAHAYA JANITRA & 90 & TUNTAS & 23 & MAHARANI USI SULISTIYOWATI & 60 & TIDAK TUNTAS \\
\hline 5 & ALVINO ANANDA PUTRA ANTORO & 70 & TIDAK TUNTAS & 24 & MOHAMAD KEVIN MAULANA & 70 & TIDAK TUNTAS \\
\hline 6 & AMELIA RAMADHANI & 80 & TUNTAS & 25 & MUHAMAD ZHIDAN SAPUTRA & 40 & TIDAK TUNTAS \\
\hline 7 & ANGGRAINI BULANDARI & 80 & TUNTAS & 26 & \begin{tabular}{|l|} 
MUHAMMAD DIN NAUFA \\
\end{tabular} & 90 & TUNTAS \\
\hline 8 & ARKAN SASHENKA AL-FATIH & 90 & TUNTAS & 27 & NEIRA NATASHA ARAWINDA WA & 90 & TUNTAS \\
\hline 9 & AULIYA SUCI RAHMADANI & 30 & TIDAK TUNTAS & 28 & \begin{tabular}{|l|l|} 
QIRINA PUTRI SAFE ORA \\
\end{tabular} & 90 & TUNTAS \\
\hline 10 & AYFI KHOIRUN NISA & 60 & TIDAK TUNTAS & 29 & QUINSHA AURELIA PUTRI & 70 & TIDAK TUNTAS \\
\hline 11 & AZLAN RAFISQY ASTRAKUSUMA & 100 & TUNTAS & 30 & RAIHAN YUSUF HABIBI & 70 & TIDAK TUNTAS \\
\hline 12 & CANDRA AKBAR PRATAMA & 80 & TUNTAS & 31 & RAMA SATRIO WICAKSONO & 80 & TUNTAS \\
\hline 13 & DESINTHA DWI ANGGARINI & 100 & TUNTAS & 32 & SATRIA BASYA & 80 & TUNTAS \\
\hline 14 & ELDIO OKTA WIBAWA & 30 & TIDAK TUNTAS & 33 & SHAFIQ AFRIANSYAH & 40 & TIDAK TUNTAS \\
\hline 15 & GAVIN PUTRA MAHESWARA & 100 & TUNTAS & 34 & SULTAN ALI FATHAN KAMIL & 40 & TIDAK TUNTAS \\
\hline 16 & HAIDAR FARUQ FARANDI & 90 & TUNTAS & 35 & SYIFA QONITINA MARFU'AH & 90 & TUNTAS \\
\hline 17 & HAURA NAVA LIBNA RAMADHANI & 90 & TUNTAS & 36 & \begin{tabular}{|l|l|} 
VICKY FARREL \\
\end{tabular} & 80 & TUNTAS \\
\hline 18 & HANAQIARA JENITA M & 70 & TIDAK TUNTAS & 37 & IBRA ALVINO PUTRA MEDITAMA & 90 & TUNTAS \\
\hline 19 & IVAN ORLYND RAMADHAN & 80 & TUNTAS & & & & \\
\hline \multicolumn{4}{|c|}{ NILAI TERTINGGI } & \multicolumn{4}{|c|}{100} \\
\hline \multicolumn{4}{|c|}{ NILAI TERENDAH } & \multicolumn{4}{|c|}{30} \\
\hline \multicolumn{4}{|c|}{ SISWA TUNTAS } & \multicolumn{4}{|c|}{22} \\
\hline \multicolumn{4}{|c|}{ SISWA TIDAK TUNTAS } & \multicolumn{4}{|c|}{15} \\
\hline \multicolumn{4}{|c|}{ RATA-RATA KELAS } & \multicolumn{4}{|c|}{73.24} \\
\hline \multicolumn{4}{|c|}{ PRESENTASE KETUNTASAN } & \multicolumn{4}{|c|}{$59 \%$} \\
\hline \multicolumn{4}{|c|}{ PRESENTASE KETIDAKTUNTASAN } & \multicolumn{4}{|c|}{$41 \%$} \\
\hline
\end{tabular}

Dari gambar di atas dapat dijelaskan bahwa dari hasil belajar pra siklus pada kelas VB tema V "Ekosistem" terdapat 37 siswa. Dari 37 siswa terdapat 22 siswa yang tuntas dan 15 siswa yang tidak tuntas dalam evaluasi pra siklus. Dari gambar 4.1 diperoleh data bahwa nilai tertinggi yang diperoleh siswa adalah 100 dan nilai terendah yang diperoleh siswa adalah 30. Dari hasil evaluasi pra siklus untuk rata-rata kelas diperoleh 73, 24 masih di bawah KKM yaitu 80. Persentase kelulusan mencapai 59\% dari $100 \%$. Sedangkan persentase ketidaklulusan sebesar $41 \%$ dari $100 \%$.

\section{Siklus 1}

Pembelajaran dilaksanakan secara daring melalui teleconverence Zoom Meeting. Dalam pelaksanaan pertama diikuti oleh 25 siswa dari 37 siswa. Hal tersebut dikarenakan banyak siswa yang tidak memiliki handphone atau smartphone pribadi. Pada pelaksanaan pembelajaran berlangsung dengan lancar sesuai dengan Rencana Pelaksanaan Pembelajaran yang telah disusun sebelumnya.

Dalam kegiatan awal pembelajaran guru memberi salam dan berdoa sebelum memulai pembelajaran. Guru memberi motivasi, apersepsi dan menyampaikan tujuan pembelajaran yang akan dicapai. Dalam kegiatan inti langkah-langkah pembelajaran sesuai dengan syntak Discovery Learning yang meliputi pemberian stimulus atau rangsangan dari masalah. Guru memberikan identifikasi masalah berupa pemberian pertanyaan yang mampu memancing keaktifan peserta didik. Peserta didik mulai mengumpulkan dan mengolah informasi terkait dengan permasalahan yang disajikan guru. Selanjutnya guru bersama peserta didik dalam pembuktian dan menarik kesimpulan dari hasil identifikasi masalah.

Pada pertemuan kedua di hari berikutnya pembeklajaran masih dilaksanakan secara daring melalui teleconverence Zoom Meeting. Padah hari kedua ini terdapat peningkatan jumlah peserta didik yang megikuti teleconverence Zoom Meeting dari 25 siswa menjadi 29 siswa. Hal ini menunjukkan antusias peserta didik dalam mengikuti pembelajaran daring sangat besar. Mengingat prosentasi $78 \%$.

Pada pelaksanaan pembelajaran masih sama pada pertemuan pertama. Akan tetapi pada pertemuan kedua dilakukan evaluasi pembelajaran melalui Google Form. Pada pelaksanaan evaluasi pembelajaran melalui Google Form dilaksanakan oleh 
seluruh peserta didik, hal tersebut dikarenakan dapat dikerjakan pada malam hari setelah orang tua peserta didik pulang kerumah. Dari hasil dalam pembelajaran Tema 5 nilai tertinggi yang diperoleh siswa adalah 100 dengan nilai terendah 30 . Ketuntasan siswa mencapai 22 siswa dengan presentasi 59\% dan ketidaktuntasan siswa sebesar 15 dengan presentase $41 \%$. Nilai rata-rata kelas secara keseluruhan adalah 73 .

Berdasrakan data hasil belajar siswa pada Siklus I diperoleh bahwa hasil belajar terti ggi 100 dan nilai terendah 40. Dari 37 siswa terdapat 10 siswa yang memeroleh 100. Dari hasil belajar siswa diperoleh dari 37 siswa terdapat 24 siswa yang tuntas dan 13 siswa yang belum tuntas. Diketahui juga bahwa nilai rata-rata kelas naik menjadi 81,08 .

Tabel 2. Rekapitulasi Hasil Belajar Siklus I

\begin{tabular}{|c|c|c|c|c|c|c|c|}
\hline NO & NAMA SISWA & NILAI & KET & NO & NAMA SISWA & NILAI & KET \\
\hline 1 & MUHAMMAD KATRI DARUSSALA & 80 & TUNTAS & 19 & IVAN ORLYND RAMADHAN & 85 & TUNTAS \\
\hline 2 & \begin{tabular}{|l|l|} 
KESYA PUPUT ARYANTI \\
\end{tabular} & 80 & TUNTAS & 20 & JALESA PRAMESH KHATAMI & 90 & TUNTAS \\
\hline 3 & ALIA SHOFIA RAHMADHANI & 80 & TUNTAS & 21 & JOVA BRATA SANJOYO & 50 & TIDAK TUNTAS \\
\hline 4 & ALMIRA ALIFIA CAHAYA JANITR & 90 & TUNTAS & 22 & KANAHAYA ZETA AZARIN & 100 & TIDAK TUNTAS \\
\hline 5 & ALVINO ANANDA PUTRA ANTOR & 90 & TUNTAS & 23 & MAHARANI USI SULISTIYOWATI & 90 & \begin{tabular}{|l|} 
TUNTAS \\
\end{tabular} \\
\hline 6 & \begin{tabular}{|l|l|} 
AMELIA RAMADHANI \\
\end{tabular} & 100 & TUNTAS & 24 & MOHAMAD KEVIN MAULANA & 80 & \begin{tabular}{|l|} 
TUNTAS \\
\end{tabular} \\
\hline 7 & ANGGRAINI BULANDARI & 60 & TIDAK TUNTAS & 25 & MUHAMAD ZHIDAN SAPUTRA & 100 & TIDAK TUNTAS \\
\hline 8 & ARKAN SASHENKA AL-FATIH & 100 & TUNTAS & 26 & MUHAMMAD DIN NAUFA & 100 & \begin{tabular}{|l|} 
TUNTAS \\
\end{tabular} \\
\hline 9 & AULIYA SUCI RAHMADANI & 60 & TIDAK TUNTAS & 27 & NEIRA NATASHA ARAWINDA WA & 90 & TUNTAS \\
\hline 10 & AYFI KHOIRUN NISA & 50 & TIDAK TUNTAS & 28 & \begin{tabular}{|l|l|} 
QIRINA PUTRI SAFE ORA \\
\end{tabular} & 60 & TIDAK TUNTAS \\
\hline 11 & AZLAN RAFISQY ASTRAKUSUMA & 90 & TUNTAS & 29 & QUINSHA AURELIA PUTRI & 80 & \begin{tabular}{|l|} 
TUNTAS \\
\end{tabular} \\
\hline 12 & CANDRA AKBAR PRATAMA & 80 & TUNTAS & 30 & RAIHAN YUSUF HABIBI & 90 & TUNTAS \\
\hline 13 & DESINTHA DWI ANGGARINI & 70 & TIDAK TUNTAS & 31 & RAMA SATRIO WICAKSONO & 50 & TIDAK TUNTAS \\
\hline 14 & ELDIO OKTA WIBAWA & 85 & TUNTAS & 32 & SATRIA BASYA & 40 & TIDAK TUNTAS \\
\hline 15 & GAVIN PUTRA MAHESWARA & 100 & TUNTAS & 33 & SHAFIQ AFRIANSYAH & 60 & TIDAK TUNTAS \\
\hline 16 & HAIDAR FARUQ FARANDI & 100 & TUNTAS & 34 & SULTAN ALI FATHAN KAMIL & 100 & TUNTAS \\
\hline 17 & HAURA NAVA LIBNA RAMADHAY & 100 & TUNTAS & 35 & SYIFA QONITINA MARFU'AH & 80 & TUNTAS \\
\hline 18 & \begin{tabular}{|l|l} 
HANAQIARA JENITA M & \\
\end{tabular} & 100 & TIDAK TUNTAS & 36 & VICKY FARREL & 50 & TIDAK TUNTAS \\
\hline 19 & IVAN ORLYND RAMADHAN & 85 & TUNTAS & 37 & IBRA ALVINO PUTRA MEDITAMA & 90 & TUNTAS \\
\hline \multicolumn{5}{|c|}{ NILAI TERTINGGI } & \multicolumn{3}{|l|}{100} \\
\hline \multicolumn{5}{|c|}{ NILAI TERENDAH } & \multicolumn{3}{|l|}{40} \\
\hline \multicolumn{5}{|c|}{ SISWA TUNTAS } & \multicolumn{3}{|l|}{24} \\
\hline \multicolumn{5}{|c|}{ SISWA TIDAK TUNTAS } & \multicolumn{3}{|l|}{13} \\
\hline \multicolumn{5}{|c|}{ RATA-RATA KELAS } & \multicolumn{3}{|l|}{81.08} \\
\hline \multicolumn{5}{|c|}{ PRESENTASE KETUNTASAN } & \multicolumn{3}{|l|}{$65 \%$} \\
\hline \multicolumn{5}{|c|}{ PRESENTASE KETIDAKTUNTASAN } & \multicolumn{3}{|l|}{$35 \%$} \\
\hline
\end{tabular}

Untuk persentase ketuntasan hasil belajar siswa secara klasikal dapat dilihat dalam diagram sebagai berikut:

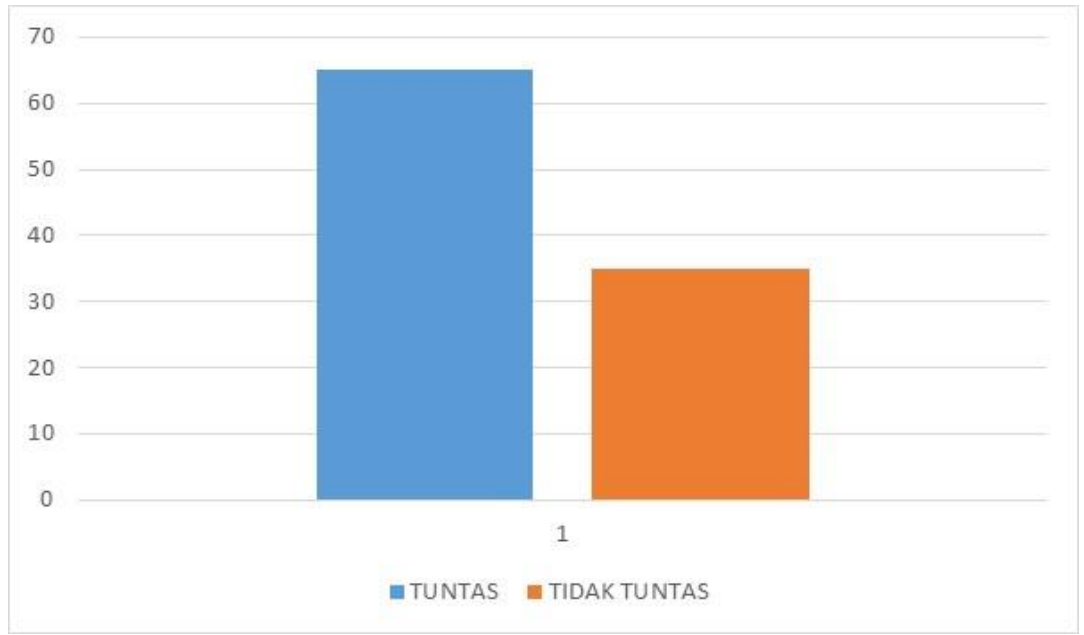

Gambar 1. Hasil Belajar Siklus I 
Berdasarkan diagram di atas, dapat dilihat bahwa persentase ketuntasan hasil belajar siswa secara klasikal pada siklus I sebesar $65 \%$, sedangkan siswa yang tidak tuntas pada pra siklus sebesar $35 \%$. Hal itu menunjukkan bahwa pada siklus I belum mencapai indikator keberhasilan ketuntasan klasikal yaitu sebesar $75 \%$, sehingga perlu dilaksanakan perbaikan melalui siklus II.

\section{Siklus II}

Pembelajaran dilaksanakan secara daring melalui teleconverence Zoom Meeting. Dalam pelaksanaan pertama diikuti oleh 30 siswa dari 37 siswa. Jumalh tersebut sudah meningkat dari siklus sebelumnya.. Dalam kegiatan awal pembelajaran guru memberi salam dan berdoa sebelum memulai pembelajaran. Guru memberi motivasi, apersepsi dan menyampaikan tujuan pembelajaran yang akan dicapai. Dalam kegiatan inti langkah-langkah pembelajaran sesuai dengan syntak Discovery Learning yang meliputi pemberian stimulus atau rangsangan dari masalah. Guru memberikan identifikasi masalah berupa pemberian pertanyaan yang mampu memancing keaktifan peserta didik. Peserta didik mulai mengumpulkan dan mengolah informasi terkait dengan permasalahan yang disajikan guru. Selanjutnya guru bersama peserta didik dalam pembuktian dan menarik kesimpulan dari hasil identifikasi masalah.

Pada pertemuan kedua di hari berikutnya pembeklajaran masih dilaksanakan secara daring melalui teleconverence Zoom Meeting. Padah hari kedua ini terdapat peningkatan jumlah peserta didik yang megikuti teleconverence Zoom Meeting dari 30 siswa menjadi 32 siswa. Presentase jumlah tersebut meningkat dari siklus .I sebesar $78 \%$ menjadi $86 \%$. Pada pelaksanaan pembelajaran masih sama pada pertemuan pertama. Akan tetapi pada pertemuan kedua dilakukan evaluasi pembelajaran melalui Google Form. Pada pelaksanaan evaluasi pembelajaran melalui Google Form dilaksanakan oleh seluruh peserta didik. Hasil data evaluasi pada siklus II diperoleh data sebagai berikut:

Tabel 3. Rekapitulasi Hasil Belajar Pra Siklus II

\begin{tabular}{|c|c|c|c|c|c|c|c|}
\hline No & NAMA SISWA & NILAI & KET & NO & NAMA SISWA & NILAI & KET \\
\hline 1 & MUHAMMAD KATRI DARUSSALA & 100 & TUNTAS & 19 & IVAN ORLYND RAMADHAN & 80 & TUNTAS \\
\hline 2 & KESYA PUPUT ARYANTI & 50 & TIDAK TUNTAS & 20 & JALESA PRAMESH KHATAMI & 100 & TUNTAS \\
\hline 3 & ALIA SHOFIA RAHMADHANI & 100 & TUNTAS & 21 & JOVA BRATA SANJOYO & 90 & TUNTAS \\
\hline 4 & ALMIRA ALIFIA CAHAYA JANITR & 100 & TUNTAS & 22 & KANAHAYA ZETA AZARIN & 90 & TUNTAS \\
\hline 5 & ALVINO ANANDA PUTRA ANTOR & 100 & TUNTAS & 23 & MAHARANI USI SULISTIYOWATI & 90 & TUNTAS \\
\hline 6 & AMELIA RAMADHANI & 100 & TUNTAS & 24 & MOHAMAD KEVIN MAULANA & 40 & TIDAK TUNTAS \\
\hline 7 & ANGGRAINI BULANDARI & 90 & TUNTAS & 25 & MUHAMAD ZHIDAN SAPUTRA & 80 & \begin{tabular}{|l|} 
TUNTAS \\
\end{tabular} \\
\hline 8 & ARKAN SASHENKA AL-FATIH & 100 & TUNTAS & 26 & MUHAMMAD DIN NAUFA & 90 & TUNTAS \\
\hline 9 & AULIYA SUCI RAHMADANI & $\mathbf{5 0}$ & TIDAK TUNTAS & 27 & NEIRA NATASHA ARAWINDA WA & 100 & TUNTAS \\
\hline 10 & AYFI KHOIRUN NISA & 100 & TUNTAS & 28 & \begin{tabular}{|l|} 
QIRINA PUTRI SAFE ORA \\
\end{tabular} & 60 & TIDAK TUNTAS \\
\hline 11 & AZLAN RAFISQY ASTRAKUSUMA & 90 & TUNTAS & 29 & QUINSHA AURELIA PUTRI & 70 & TIDAK TUNTAS \\
\hline 12 & CANDRA AKBAR PRATAMA & 90 & TUNTAS & 30 & RAIHAN YUSUF HABIBI & 90 & \begin{tabular}{|l|} 
TUNTAS \\
\end{tabular} \\
\hline 13 & DESINTHA DWI ANGGARINI & 100 & TUNTAS & 31 & RAMA SATRIO WICAKSONO & 50 & TIDAK TUNTAS \\
\hline 14 & ELDIO OKTA WIBAWA & 40 & TIDAK TUNTAS & 32 & SATRIA BASYA & 60 & TIDAK TUNTAS \\
\hline 15 & GAVIN PUTRA MAHESWARA & 100 & TUNTAS & 33 & SHAFIQ AFRIANSYAH & 50 & TIDAK TUNTAS \\
\hline 16 & HAIDAR FARUQ FARANDI & 100 & TUNTAS & 34 & SULTAN ALI FATHAN KAMIL & 80 & \begin{tabular}{|l|l} 
TUNTAS \\
\end{tabular} \\
\hline 17 & HAURA NAVA LIBNA RAMADHAN & 100 & TUNTAS & 35 & SYIFA QONITINA MARFU'AH & 80 & TUNTAS \\
\hline 18 & HANAQIARA JENITA M & 100 & TUNTAS & 36 & VICKY FARREL & 80 & TUNTAS \\
\hline & & & & 37 & IBRA ALVINO PUTRA MEDITAMA & 90 & TUNTAS \\
\hline \multicolumn{5}{|c|}{ NILAI TERTINGGI } & \multicolumn{3}{|l|}{$\begin{array}{r}100 \\
\end{array}$} \\
\hline \multicolumn{5}{|c|}{ NILAI TERENDAH } & \multicolumn{3}{|l|}{40} \\
\hline \multicolumn{5}{|c|}{ SISWA TUNTAS } & \multicolumn{3}{|l|}{28} \\
\hline \multicolumn{5}{|c|}{ SISWA TIDAK TUNTAS } & \multicolumn{3}{|l|}{9} \\
\hline \multicolumn{5}{|c|}{ RATA-RATA KELAS } & \multicolumn{3}{|l|}{83.24} \\
\hline \multicolumn{5}{|c|}{ PRESENTASE KETUNTASAN } & \multicolumn{3}{|l|}{$78 \%$} \\
\hline \multicolumn{5}{|c|}{ PRESENTASE KETIDAKTUNTASAN } & \multicolumn{3}{|l|}{$22 \%$} \\
\hline
\end{tabular}

Dari Gambar di atas dapat diperoleh data hasil belajar siswa pada siklus II sebagai berikut:

1. Nilai tertinggi yang diperoleh siswa adalah 100 dengan jumlah 14 siswa

2. Nilai terendah yang diperoleh siswa adalah 40 dengan jumlah 2 siswa

3. Jumlah siswa yang tuntas mencapai 28 siswa dengan presentase ketuntasan $78 \%$ 
4. Jumlah siswa yang tidak tuntas mencapai 9 siswa dengan presentase $22 \%$

5. Rata-rata nilai yang diperoleh kelas adalah 83,24

Untuk persentase ketuntasan hasil belajar siswa secara klasikal dapat dilihat dalam tabel sebagai berikut :

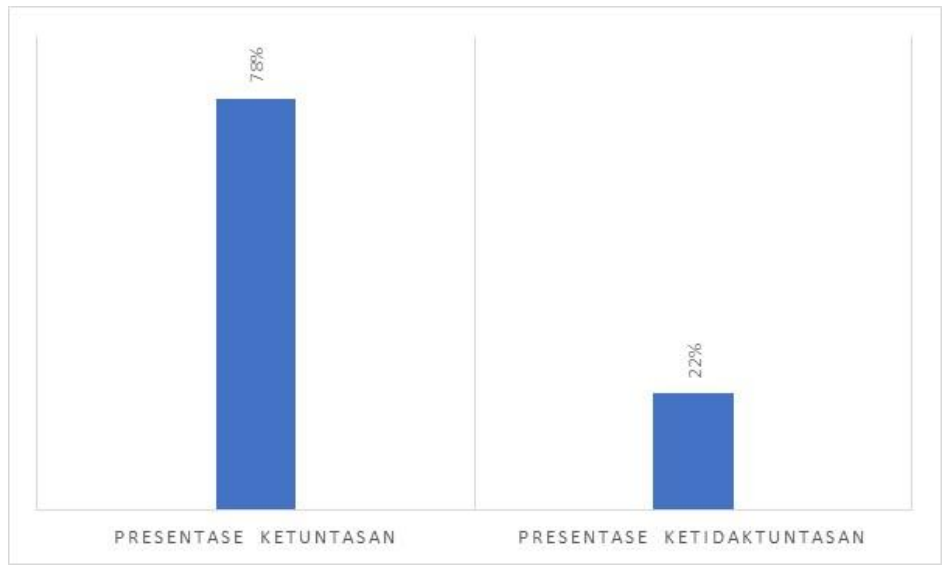

Gambar 2. Hasil Belajar Siswa

Berdasarkan gambar 2, dapat dilihat bahwa persentase ketuntasan hasil belajar siswa secara klasikal pada siklus I sebesar $78 \%$, sedangkan siswa yang tidak tuntas pada pra siklus sebesar $22 \%$. Hal itu menunjukkan bahwa pada siklus II sudah mencapai indikator keberhasilan ketuntasan klasikal yaitu sebesar $75 \%$.

\section{SIMPULAN}

Telah terjadi peningkatan hasil belajar peserta didik pembelajaran Tema 5 melalui Video pembelajaran berbasis Model Discovery Learning pada siswa kelas VB SDN Petompon 02 Semarang. Hasil ini terlihat dari rata-rata kelas pada Siklus I sebesar 81 dengan presentase ketuntasan $65 \%$. Untuk hasil pada Siklus II mengalami peningkatan dari nilai rata-rata kelas menjadi $83,24 \%$ dengan presentase ketuntasan naik menjadi $78 \%$. Berdasarkan hasil Penelitian Tindakan Kelas yang telah dilaksanakan, peneliti memberikan beberapa saran. Guru lebih tanggap kepada siswa yang mengganggu pembelajaran sehingga kelas menjadi lebih kondusif. Media dapat dibuat lebih menarik lagi sehingga siswa lebih tertarik mengikuti pembelajaran Permasalahan yang diberikan disesuaikan dengan tingkat perkembangan siswa sehingga siswa dapat mengembangkan keterampilan berpikir kritis dan keterampilan menyelesaikan masalah. Guru perlu memberikan tindak lanjut berupa kegiatan remedial bagi siswa yang belum tuntas dan pengayaan bagi siswa yang sudah tuntas. 


\section{DAFTAR PUSTAKA}

Undang-Undang Republik Indonesia Nomor 20 Tahun 2003. Sisdiknas: https://peraturan.bpk.go.id

Sukajati, 2008. Penelitian Tindakan Kelas SD. Jogjakarta: Pusat pengembangan dan Pemberdayaan pendidikan dan tenaga kependidikan Matematika.

Riyadi, Muchlisin. 2017 https://www.kajianpustaka.com/2017/09/metode-pembelajaranpenemuan-discovery-learning.html diakses pada tanggal 31/Okteber/2020

Anonim, 2017. http://meaningaccordingtoexperts.blogspot.com/2017/04 /pengertianmedia-video-pembelajaran.html diakses pada tanggal 20/Okteber/2020

Wardani, I G A K (2020). Materi Pokok Tindakan Kelas. Tangerang Selatan. Universitas Terbuka.

Suryanto, Adi (2019). Materi pokok evaluasi pembelajaran di SD. Tangerang Selatan. Universitas Terbuka.

Anitah W., Sri. Materi Pokok Strategi Pembelajaran di SD. Tangerang Selatan. Universitas Terbuka 